\title{
Core learning outcomes in sexual and reproductive health and HIV for medical undergraduates: improving skills of future providers
}

I we are to implement enduring and comprehensive improvement in the knowledge, skills, and attitudes of healthcare professionals in sexual and reproductive health and HIV, we must focus on defining and raising the baseline competencies of all future sexual healthcare providers by influencing the content and delivery of undergraduate education. Sexual and reproductive health are key determinants of a person's wellbeing and yet are often overlooked during medical consultations. We need to ensure a baseline of competence in sexual health for all doctors, not just those formally working as sexual healthcare providers.

Current provision of sexual and reproductive health and HIV teaching in the UK medical undergraduate curricula is patchy and appears to have changed little in the past 10 years. As the first step in addressing these inequalities, BASHH created an undergraduate education working group to define the minimum acceptable level of knowledge, skills, and attitudes required by newly qualified pre-registration house officers (PRHOs) to practise competently when assessing patients with sexual, reproductive, and HIV associated problems and needs. The group then expanded to include representatives from British HIV Association (BHIVA), British Infection Society (BIS), and Faculty of Family Planning and Reproductive Health Care (FFPRHC), and a senior academic in medical education. The resulting document, Core learning outcomes in sexual and reproductive health and HIV for medical undergraduates entering PRHO training was timed to coincide with and to inform the General Medical Council's extensive review of PRHO training (see STI website for copy of leaflet (www.stijournal. com/supplemental)).

We believe that this consensus definition should be used both in a top down approach by influencing the curriculum planners and policy makers, and from the bottom up where, as teachers, we can use it as a standard against which to measure current sexual health education provision in our own medical schools. If gaps are identified, the standards could become a powerful tool to justify additional curriculum space or teaching resources. It is important to emphasise that these learning outcomes refer to knowledge acquired throughout the undergraduate curriculum. Where, when, and by whom the content is delivered will depend on local resources and expertise and may involve teachers from a range of disciplines and specialties.

Two other BASHH initiatives support the core learning outcomes: The toolkit for sexual history taking in the undergraduate curriculum and STIFUndergrad, which is an adaptation of the STIF materials and teaching methods for undergraduate learners. Both are available to BASHH members via the website. Finally, Self assessed knowledge and skills in sexual health and HIV in PRHOs is an ongoing postal survey of all UK PRHOs. The results will form a benchmark against which we can measure the impact of introduction of the core learning outcomes in future years.

Finding time and enthusiasm to teach undergraduates when faced with ever mounting clinical pressures is a considerable challenge. However, it is only by equipping all our graduates with the appropriate knowledge, skills, and attitudes that we can realistically expect to raise standards in sexual health care in a comprehensive and sustainable way.

\section{ACKNOWLEDGEMENTS}

The core learning outcomes have resulted from a huge team effort: BASHH Undergraduate Education Working Group (Jyoti Dhar, Loay David, Anne Edwards, Claudia Estcourt, David Goldmeier, Paddy Horner, Helen Mitchell, Melinda TenantFlowers, Nick Theobald), British HIV Association (BHIVA): Jane Anderson, British Infection Society (BIS): Nick Beeching: Faculty of Family Planning and Reproductive Health Care (FFPRHC): Chris Wilkinson. We also thank Angela Robinson for her continued enthusiasm and support for all the BASHH undergraduate education initiatives.

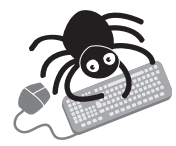

See STI website www. stijournal.com/supplemental for copy of Core learning outcomes leaflet.

C Estcourt
Centre for Infectious Disease, ICMS, Barts and
the London Queen Mary's School of Medicine
and Dentistry, London E1 2AT, UK
C Estcourt, D E Evans
Infection and Immunity, Barts and the London
NHS Trust, London, UK
D E Evans
Institute of Health Sciences Education, Barts and
the London, London, UK
Correspondence to: Dason E Evans, Institute of
Health Sciences Education, Barts and the
London Queen Mary's School of Medicine and
Dentistry, St Bartholomew's Hospital, Robin
Brook Centre, London EC1 7BE, UK;
d.e.evans@qmul.ac.uk

Conflict of interest: the authors have no conflict of interest. 